\title{
Los desafíos de la Unión Europea en la gobernanza global
}

\author{
Dr. Rafael García Pérez \\ Profesor Titular de Relaciones Internacionales \\ Facultad de Ciencias Políticas \\ Universidad de Santiago de Compostela
}

\begin{abstract}
Sumario: I. Introducción. - II. Ambición europea al inicio del siglo XXI. -III. Limites del proyecto europeo.-IV. Repensar la política europea. 1. La pérdida de capacidad de atracción europea en Naciones Unidas. 2. La difícil reforma de las organizaciones económicas internacionales. $-\mathrm{V}$. Reflexiones finales.
\end{abstract}

Resumen: Para la UE la gobernanza global constituye mucho más que un procedimiento colectivo de gestión y de toma de decisiones a nivel internacional. Representa también una propuesta política sobre cómo ordenar y gestionar la convivencia internacional. Al inicio del nuevo siglo la UE fue muy activa en la reforma de las organizaciones internacionales, pero tras la crisis política (2005) y financiera (2008) la UE ha perdido impulso político y encuentra múltiples dificultades para realizar ese programa. Si no quiere perder influencia, la UE debe adaptar sus objetivos políticos a la nueva realidad internacional.

Palabras clave: Unión Europea, gobernanza global, política exterior de la UE, orden internacional, reforma instituciones internacionales.

Abstract: For the EU global governance is much more than a collective procedure for management and decision-making at the international level. It is also a political proposal on how to sort out and manage international coexistence. At the beginning of the new century the EU was very active in the reform of the international organizations, but after the political (2005) and financial (2008) crisis the Union has lost political impetus and found many difficulties to carry out this programme. If the EU does not want to lose influence, it must adapt its political objectives to the new international reality.

Keywords: European Union, global governance, EU foreign policy, international order, international institutions reform.

\section{Introducción}

Para la Unión Europea (UE), el concepto de gobernanza global no constituye tan sólo un procedimiento colectivo de gestión y de toma de decisiones internacionales con el que normalmente es identificado este con- 
cepto en términos académicos ${ }^{1}$. Representa también una determinada visión del mundo. Una interpretación racionalizada del proceso de globalización al que estamos asistiendo con particular intensidad al menos desde el fin de la guerra fría. Y es también una propuesta política sobre cómo organizar el orden internacional y el papel que la Unión debe representar en él como nuevo actor internacional sui generis.

Según una interpretación habitual del proceso al que denominamos globalización, este conjunto de transformaciones globales habría alterado la correspondencia necesaria entre los espacios económico, social y político que con anterioridad se registraba en torno a un espacio geográfico único: el Estado-nación. En el mundo de la globalización, sin embargo, el mercado tiende a ampliarse a escala planetaria sin que el espacio político y social haya podido seguir esta tendencia al mismo ritmo. En consecuencia, se ha producido una divergencia creciente entre el espacio económico mundializado, y los espacios político y social que siguen confinados en las tradicionales fronteras nacionales. ¿Cómo volver a reajustar estos tres espacios para recuperar la correspondencia entre ellos? Una propuesta, difícilmente aplicable, sería la construcción de una sociedad planetaria. Una cosmópolis ${ }^{2}$ en la cual las dimensiones económica, social y política volvieran a reencontrarse en un espacio mundial único y común. Una alternativa pragmática, y muy europea, a esta utopía planetaria es la gobernanza global. Un proyecto de organización de la sociedad internacional absolutamente coherente con las formas y procedimientos sobre los que se ha construido y gobierna la Unión, basado en la promoción de instancias colectivas de participación y decisión supraestatales.

Frente a otras formas tradicionales de gestión de los sistemas internacionales multipolares, asentadas principalmente en el equilibrio de poder, la UE ofrecía una vía alternativa cuyo fundamento es la integración de los Estados en una instancia de gobernanza superior basada en el Derecho, la democracia, la seguridad, el desarrollo y los Derechos Humanos ${ }^{3}$. De hecho, la propuesta europea de gobernanza global venía avalada por el éxito alcanzado en su propia experiencia de integración y era coherente con el Zeitgeist de nuestra época. La globalización, al fin y al cabo, nos conducía hacia un mundo post-moderno (en el sentido de post-westfaliano) que borraba las fronteras entre política interior y exterior, redefinía el concepto de sobe-

${ }^{1}$ Conjunto de prácticas a través de las cuales, determinadas áreas de problemas internacionales tratan de ser gestionadas por medio de una serie de reglas pactadas colectivamente entre actores de distinta naturaleza y que no emanan de una autoridad formalmente constituida.

${ }^{2}$ MATTELART, A., Cosmópolis. Perspectivas y riesgos de un gobierno mundial. Paidós, Barcelona, 2000.

3 COOPER, R., The Postmodern State and the World Order. Demos, Londres, 2000. 
ranía y ponía en cuestión la propia pervivencia de los Estados-nación en la forma en que los conocemos hasta la actualidad ${ }^{4}$.

\section{Ambición europea al inicio del siglo XXI}

Aunque Europa no haya sido la exclusiva generadora de éstas ideas, ni haya sido tampoco el único actor en impulsarlas, resulta evidente la impronta europea que desprenden los conceptos sobre los que se trata de construir esta propuesta de nueva convivencia internacional: la seguridad humana ${ }^{5}$ y la paz positiva, la responsabilidad de proteger y el desarrollo humano ${ }^{6}$, o el Derecho cosmopolita ${ }^{7}$ en defensa de unos Derechos Humanos universales y de los bienes públicos globales. La Unión Europea ofrecía su know-how en la materia, a partir de las lecciones aprendidas en su propio proceso de integración, para aplicar esta nueva lógica en la gestión de los asuntos internacionales y construir una sociedad internacional basada en el Derecho, en tanto que «contrato social», para la realización del interés general de la humanidad ${ }^{8}$.

Por eso puede afirmarse que la gobernanza global ha sido, también, una propuesta europea para organizar el orden internacional. Una propuesta que refleja los intereses y necesidades de la Unión, que trataba de proyectar sobre el conjunto del sistema internacional sus propios valores y su cosmología, y que se ofrecía como alternativa a otras propuestas de orden internacional con las que competía en el momento en que fue formulada. La intención europea de convertir a la gobernanza global en el fundamento del nuevo orden mundial aparece expresamente reflejada en numerosos documentos comunitarios de comienzos del nuevo siglo.

En el Libro Blanco sobre la Gobernanza Europea, la Comisión ya apuntaba que Europa debía «reformar con éxito su gobernanza interna si quiere propugnar el cambio a escala internacional» ${ }^{9}$ y fijaba, expresamente un programa de actuación impulsando

${ }^{4}$ COOPER, R., La fracture des nations: ordre et chaos au XXIe siècle. Denoël, Paris, 2004, pp. 44-48.

5 KALDOR, M., El poder y la fuerza. La seguridad de la población civil en el mundo global. Tusquets, Barcelona, 2010.

${ }^{6}$ SEN, A., Desarrollo y libertad. Planeta, Barcelona, 2000.

7 HELD, D., La Democracia y el orden global: del Estado moderno al gobierno cosmopolita. Paidós, Barcelona, 1997.

${ }^{8}$ MONTOBBIO, M., Salir del callejón del gato: la deconstrucción de Oriente y Occidente y la gobernanza global. Icaria, Barcelona, 2008.

9 COMISIÓN EUROPEA, La Gobernanza Europea (Un libro blanco) (COM 2001428 final) Bruselas, 25.7.2001 (http://eur-lex.europa.eu/LexUriServ/site/es/com/2001/com2001_ 0428es01.pdf), p. 31 (énfasis en el original). 
«un debate sobre la manera en que la Unión puede contribuir a una reforma en profundidad de las organizaciones multilaterales, y mejorar la cooperación entre las organizaciones internacionales y su transparencia» ${ }^{10}$.

En un sentido semejante, aunque con un lenguaje más rotundo, se expresaba la Declaración de Laeken al interrogarse si

«¿No debería Europa, ahora por fin unificada, desempeñar un papel de liderazgo en un nuevo orden planetario, el de una potencia a la vez capaz de desempeñar una función estabilizadora a nivel mundial y de ser punto de referencia para numerosos países y pueblos?» ${ }^{11}$

Idéntica ambición se mostraba en la Estrategia Europea de Seguridad cuando se afirmaba que «Europa tiene que estar dispuesta a asumir su responsabilidad en el mantenimiento de la seguridad mundial y la construcción de un mundo mejor» ${ }^{12}$, asumiendo como principal objetivo «el desarrollo de una sociedad internacional más fuerte, con instituciones internacionales que funcionen adecuadamente, y de un orden internacional basado en el Derecho» y utilizando a las «organizaciones, regímenes y tratados internacionales eficaces» para construir «un orden internacional basado en el multilateralismo eficaz» ${ }^{13}$.

La formulación explícita de estos designios quedó reflejada en el Tratado constitucional. Al definir la UE cuales eran sus objetivos, en el apartado 4 del artículo I-3 se afirmaba:

«En sus relaciones con el resto del mundo, la Unión afirmará y promoverá sus valores e intereses. Contribuirá a la paz, la seguridad, el desarrollo sostenible del planeta, la solidaridad y el respeto mutuo entre los pueblos, el comercio libre y justo, la erradicación de la pobreza y la protección de los derechos humanos, especialmente los derechos del niño, así como al estricto respeto y al desarrollo del Derecho Internacional, en particular el respeto de los principios de la Carta de las Naciones Unidas.»

10 Ibid., p. 32. El documento también abogaba por «Mejorar el diálogo con los agentes gubernamentales y no gubernamentales de los terceros países en el marco de la elaboración de propuestas políticas que revistan una dimensión internacional. (Y) Fomentar la utilización de nuevos instrumentos a escala mundial como complemento al Derecho internacional vinculante.»

${ }_{11}$ Conclusiones de la Presidencia. Consejo Europeo de Laeken, 14 y 15 de diciembre de 2001.

12 ESTRATEGIA EUROPEA DE SEGURIDAD, Una Europa segura en un mundo mejor (15895/2003 PESC 787). Bruselas, 8.12.03 (http://ue.eu.int/uedocs/cmsUpload/031208ESSIIES. pdf), p. 1.

13 Ibid., p. 9. 
Y de forma más detallada, al exponer la acción exterior de la Unión, en el artículo III-292 se desarrollaban los distintos elementos que debían conformar esta política de responsabilidad estabilizadora de la globalización que debía

«promover un sistema internacional basado en una cooperación multilateral sólida y en una buena gobernanza mundial» ${ }^{14}$.

Como destacaba el profesor Aldecoa ${ }^{15}$, con esta esperanzada declaración de principios y objetivos, la Unión Europea manifestaba su «voluntad de cambiar el sistema internacional» tratando de hacer «gobernable» la globalización, ejecutando, para lograrlo, una política exterior basada en las siguientes líneas de acción: universalidad de los valores de la Unión, proyección externa del modelo social europeo y exportación de su modelo de estabilidad, y para lograrlo promover la regulación del sistema internacional a través de la cooperación multilateral.

Resulta apreciable, por tanto, que durante el primer lustro del siglo XXI, la UE se concibió a sí misma como un nuevo actor internacional capaz de servir como fuerza estabilizadora a nivel mundial y convertirse en referente de la globalización. En este ambicioso programa europeo de política exterior, la gobernanza global desempeñaba un papel verdaderamente central al constituir tanto un principio interpretativo, respecto del destino final al que nos conducía la globalización, como normativo, al prescribir las pautas que debían regir el gobierno de la globalización. De este modo, la Unión se dotaba de un discurso y de un programa de acción.

La propuesta europea para cambiar el orden internacional se encontraba en competencia con otras alternativas, lanzadas en la misma época por otros actores relevantes, sobre cómo organizar la convivencia internacional. La principal de todas ellas fue el proyecto de unilateralismo hegemónico impulsado por los Estados Unidos durante la presidencia de George W. Bush.

La determinación del gobierno estadounidense al promover este unilateralismo por medios bélicos, lo cual llevaba implícito la extensión del modelo socio-económico norteamericano de corte neoliberal, favoreció que

14 Tratado por el que se establece una Constitución para Europa. Madrid, Ministerio de Asuntos Exteriores y de Cooperación, 2004; artículo I-3.4 y III-292.2.h, respectivamente (artículos 2.5 y 10-A.2.h del vigente Tratado de Lisboa).

15 ALDECOA, F., La gobernanza mundial como objetivo explícito de la Unión Europea en el Tratado constitucional, VII Congreso Español de Ciencia Política y de la Administración: Democracia y Buen Gobierno, 2005 (www.aecpa.es/uploads/files/congresos/ congreso_07/area06/GT29/ALDECOA-LUZARRAGA-Francisco(UCM).pdf). 
muchos actores internacionales relevantes lo percibieran como una amenaza a sus propios intereses y respaldaran, en consecuencia, toda propuesta defensora de la multipolaridad y la multilateralidad, como un medio para bloquear el designio unipolar. Sin duda alguna, durante los años que siguieron a la invasión de Iraq, la Unión Europea se benefició, en su proyección internacional, del desprestigio y rechazo que concitó la actuación estadounidense, logrando apoyos coyunturales a sus propuestas multilateralistas de reforma del orden internacional. Aunque resulta dudoso que el apoyo prestado por esos otros actores, en especial los países emergentes, compartiera los objetivos y valores europeos en el largo plazo.

\section{Limites del proyecto europeo}

Los límites de esta convergencia coyuntural de intereses entre actores internacionales tan heterogéneos en su confrontación con las aspiraciones hegemónicas estadounidenses pronto se pusieron de manifiesto cuando se trató de llevar a la práctica el programa de reforma de las principales organizaciones internacionales que había sido enunciado en el Libro Blanco del verano de 20016. El intento de reforma de las Naciones Unidas en 2005, impulsado por el entonces Secretario General Kofi Annan ${ }^{17}$, contó con el respaldo de la UE y de un número significativo de otros actores internacionales relevantes sin que consiguiera materializarse en la práctica. Los escándalos que afectaban a la Organización, y que salpicaban al propio Annan ${ }^{18}$, y la ausencia de consensos básicos previos favorecieron que a lo largo de las negociaciones se pusieran de manifiesto profundas divergencias que acabaron por dar al traste con la reforma ${ }^{19}$.

Una de las cuestiones clave donde quedó encallada la reforma fue en la transformación del Consejo de Seguridad. El documento propuesto por Annan ${ }^{20}$ conseguía sintetizar en dos fórmulas alternativas las muchas propues-

16 Vid. supra nota 9.

17 El ambicioso programa de reformas fue expuesto en el documento que sirvió de discusión a la Cumbre Mundial reunida en Nueva York en septiembre de 2005: NN.UU., Un concepto más amplio de libertad: desarrollo, seguridad y derechos humanos. Informe del Secretario General. Nueva York, 21 de marzo de 2005 (A/59/2005) (www.un.org/spanish/largerfreedom// report-largerfreedom.pdf).

18 FRATTINI, E., ONU. Historia de la corrupción. Espasa, Madrid, 2005, pp. 280-300.

19 GRANELL, F., «Naciones Unidas: reforma y transformación», Política Exterior n. ${ }^{\circ}$ 108/2005, pp. 97-104.

20 NN.UU., Un mundo más seguro: la responsabilidad que compartimos. Informe del Grupo de Alto Nivel sobre las amenazas, los desafíos y el cambio. Nueva York, 2 de diciembre de 2004 (A/59/565) (www.un.org/spanish/secureworld/report_sp.pdf). 
tas barajadas inicialmente (ver tabla 1). Las dos pretendían atribuir una representación idéntica (seis puestos) a cada una de las cuatro grandes regiones del planeta (África, América, Asia-Pacífico y Europa), de manera que el número total de miembros del Consejo se ampliaría de 15 a 24. Ambas propuestas divergían, sin embargo, en cuanto a la naturaleza permanente, electiva renovable y no renovable de los nuevos miembros, respetando, en todo caso, la pervivencia de los cinco miembros permanentes con derecho a veto ya existentes ${ }^{21}$.

\section{Tabla 1}

Reforma del Consejo de Seguridad (2004)

Propuesta A

\begin{tabular}{l|cccc|c}
\hline \multicolumn{1}{c|}{ Región } & $\begin{array}{c}\mathrm{N}^{\circ} \\
\text { de estados }\end{array}$ & $\begin{array}{c}\text { Puestos } \\
\text { permanentes }\end{array}$ & $\begin{array}{c}\text { Nuevos } \\
\text { puestos } \\
\text { permanentes }\end{array}$ & $\begin{array}{c}\text { Puestos con } \\
\text { mandato } \\
\text { No renovable } \\
\text { (2 Años) }\end{array}$ & Total \\
\hline África & 53 & 0 & 2 & 4 & 6 \\
Asia-Pacífico & 56 & 1 & 2 & 3 & 6 \\
Europa & 47 & 3 & 1 & 2 & 6 \\
América & 35 & 1 & 1 & 4 & 6 \\
\hline Total & 191 & 5 & 6 & 13 & 24 \\
\hline
\end{tabular}

Propuesta B

\begin{tabular}{l|cccc|c}
\hline \multicolumn{1}{c|}{ Región } & $\begin{array}{c}\text { N. }{ }^{\circ} \\
\text { de estados }\end{array}$ & $\begin{array}{c}\text { Puestos } \\
\text { permanentes }\end{array}$ & $\begin{array}{c}\text { Nuevos } \\
\text { puestos } \\
\text { permanentes }\end{array}$ & $\begin{array}{c}\text { Puestos con } \\
\text { mandato } \\
\text { No renovable } \\
\text { (2 Años) }\end{array}$ & Total \\
\hline África & 53 & 0 & 2 & 4 & 6 \\
Asia-Pacífico & 56 & 1 & 2 & 3 & 6 \\
Europa & 47 & 3 & 2 & 1 & 6 \\
América & 35 & 1 & 2 & 3 & 6 \\
\hline Total & 191 & 5 & 8 & 11 & 24 \\
\hline
\end{tabular}

Fuente: Un mundo más seguro: la responsabilidad que compartimos.

${ }^{21}$ Según la primera alternativa (propuesta A) habría seis nuevos puestos permanentes, pero sin derecho a veto, que corresponderían a países como Alemania, Brasil, Egipto, India, Japón, México o Sudáfrica (los candidatos no eran mencionados en el informe). A ellos habría que añadir tres nuevos puestos no permanentes (que se sumarían a los 10 existentes en la actualidad), que serían elegidos por un mandato de dos años de duración. La segunda alternativa (propuesta B) proponía elegir ocho miembros por un mandato renovable de cuatro años y un nuevo puesto con un mandato de dos años no renovable. 
La principal dificultad a la que se enfrentó la reforma fue que el número de países candidatos a hacerse con un puesto en el Consejo superaba ampliamente al número de plazas disponibles. El documento sugería algunos criterios que la Asamblea General podía seguir para proceder a la designación ${ }^{22}$. Pero la aplicación de estos criterios planteaba dudas sobre su equidad: los países pobres se sentían discriminados respecto de los ricos, y los de menor tamaño frente a los de mayor población. Pero, sobre todo, esos criterios no permitían dar satisfacción a todos los candidatos. ¿Cómo atribuir el único nuevo puesto permanente que correspondería al continente americano según la primera opción? ¿O cómo distribuir los dos puestos atribuidos a la región Asia-Pacífico? Resulta muy difícil que países como México, Brasil o Argentina, en el primer caso, o Japón, India, Australia, Pakistán o Indonesia, en el segundo, aceptaran someterse a un estándar de selección de esa naturaleza.

Pero no podemos olvidar que el punto de partida de la reforma era el mantenimiento de los privilegios otorgados en 1945 a los vencedores en la Guerra Mundial por la Carta. Si este fue el mayor intento de reforma institucional, en verdad que tenía poco recorrido al consagrar una desigualdad esencial que claramente privilegiaba a los Estados más poderosos, dos de ellos miembros de la UE. Una lectura complaciente desde Europa tal vez pueda atribuir todas las responsabilidades del fracaso a la resistencia mostrada por el gobierno estadounidense de la época, que mostraba una profunda desconfianza respecto de la ONU y estuvo simbolizada en la actitud obstruccionista mantenida por el embajador John Bolton ${ }^{23}$. O también se podía achacar el fracaso a las ambiciones nacionales de los países que competían por lograr un asiento permanente. Pero visto desde fuera de Europa, determinados países europeos compartían igualmente las culpas de frustrar la reforma al empeñarse en conservar un statu quo que les beneficia y que se traduce en una sobrerrepresentación europea en el Consejo. Como es bien sabido, el proyecto de renovación fue abandonado y así permanece desde entonces.

Tampoco se lograron avances en los intentos de reforma de otras organizaciones internacionales con anterioridad a 2008. Tanto en el Fondo Mo-

22 Por ejemplo, que para cubrir los nuevos puestos permanentes o los de mayor duración se diera preferencia a aquellos Estados que se encontraran entre los tres mayores contribuyentes regionales al presupuesto ordinario de la organización o que, en su defecto, figuraran entre los mayores contribuyentes voluntarios o los que mayor número de efectivos aportan a las misiones de paz de las Naciones Unidas, dentro de sus respectivas regiones.

${ }^{23}$ Para un análisis de la posición estadounidense vid. MENDELSON FORMAN, J., ¿Podrá salvar la reforma a la ONU? Real Instituto Elcano (Documento de trabajo n. ${ }^{\circ}$ 40/2005 de 17.10.2005); y KERN, S., ¿Se reformará la ONU? Real Instituto Elcano (Análisis n. ${ }^{\circ} 131 / 2005$ de 14.11 .2005$)$. 
netario Internacional (FMI) como en el Banco Mundial (BM) la principal resistencia a los cambios vino, en este caso, de los propios países europeos, reticentes a ceder «sillas» y cuota de voto a otras partes del mundo. Como tampoco se avanzó en la reforma de otros foros informales que, como el G-7, tal vez por su propia naturaleza, hubieran sido más accesibles a su implicación en proyecto de gobernanza.

El balance de los resultados materiales del programa político enunciado por la Unión al inicio del nuevo siglo para lograr un orden internacional de gobernanza global no había prosperado especialmente antes de 2008. Y la responsabilidad de ese fracaso no es posible atribuirla exclusivamente a los actores extra-europeos. En todas las ocasiones la UE se enfrentó a una contradicción, no superada hasta el momento, que hace divergir a los intereses particulares de los Estados miembros (algunos de ellos, al menos, y en cada caso particular) y los objetivos generales enunciados por la Unión. A estas dificultades de base se le fueron sumando nuevos problemas. A mediados de esta primera década del siglo XXI resultó apreciable una pérdida de impulso político por parte de la UE, tanto en el plano interno como en su proyección exterior, del cual la fracasada reforma de NN.UU. fue sólo un ejemplo. Seguramente, el punto de inflexión que marca el cambio de tendencia en el pulso político europeo fue el rechazo al Tratado constitucional manifestado en los referendos negativos de Francia y Holanda en 2005, que sumieron a la Unión en una profunda crisis institucional y política que acabó por condicionar su proyección exterior, que se vio crecientemente subordinada a los Estados Unidos, especialmente tras la victoria electoral de Barak Obama en el otoño de 2008. Pero lo que acaba marcando un nuevo escenario internacional, completamente diferente al anterior, es el estallido de la crisis financiera de dimensión «global» ese mismo año ${ }^{24}$.

La crisis va a tener el efecto inmediato de cambiar radicalmente el estado de ánimo de los europeos modificando la percepción que se tenía hasta ese momento sobre el nuevo mundo impulsado por la globalización y sobre su papel en él como «actor global». Del optimismo autocomplaciente que se manifestaba al inicio del siglo ${ }^{25}$, se pasó al pesimismo de manera abrupta ${ }^{26}$, instalándose en la conciencia europea actual el convencimiento de un de-

${ }^{24}$ STIGLITZ, J., Caída libre. El libre mercado y el hundimiento de la economía mundial. Punto de Lectura, Madrid, 2011, p. 70.

25 Vid. por ejemplo: LEONARD, M., Por qué Europa liderará el siglo XXI. Taurus, Madrid, 2005; RIFKIN, J., El sueño europeo. Paidós, Barcelona, 2004.

26 SENDAGORTA, F., Europa entre dos luces ¿Declive o resurgimiento? Biblioteca Nueva, Madrid, 2007; YOUNG, R., Europe's Decline and Fall. The Struggle Against Global Irrelevance. Profile Books, Londres, 2010. 
clive inevitable, de una «dulce decadencia» ${ }^{27}$ que condena a la Unión a la práctica irrelevancia internacional.

Desde el momento mismo de su estallido, la crisis va a ser contemplada en Europa como un cataclismo. Un «parteaguas de la historia» ${ }^{28}$. Un «giro geopolítico de dimensiones históricas que está alterando el equilibrio de poder en el mundo de manera irrevocable» ${ }^{29}$. Frente a la anterior comprensión de la globalización como un fenómeno «post-moderno» pasa a ser percibida como un fenómeno «geopolítico» ${ }^{30}$ que promueve unas condiciones de reparto de la riqueza mundial que por vez primera en muchos siglos favorecen a los países no occidentales. La globalización ya no beneficia a Occidente ${ }^{31}$, y la actual crisis no hace sino acelerar esta dinámica haciendo irreversible el proceso. La consecuencia derivada es el ascenso de Asia como nuevo poder geopolítico ${ }^{32}$ y el irremediable declive europeo.

La posibilidad de ser superados por los países emergentes y no poder ocupar un lugar central, definitorio del orden internacional, ha generado una creciente angustia en el seno de la UE que se ve reflejada, entre otros documentos, en el informe del grupo de reflexión presidido por Felipe González presentado al Consejo Europeo en junio de 2010 bajo el título: Proyecto Europa 2030.

«En los próximos veinte años, no sólo habrá varios polos de poder, sino que el centro de gravedad del mundo se habrá desplazado también: hacia Asia y el sur del planeta» (...) «la Unión y sus Estados miembros podrían caer en la marginación y volverse una península occidental del continente asiático, cada vez más insignificante» ${ }^{33}$.

${ }^{27}$ Felipe González, en su intervención ante el congreso «La respuesta tecnológica al desarrollo sostenible» celebrado en Sevilla en junio de 2008, declaró que el modelo de desarrollo que hizo de Europa una potencia a mitad del siglo xx hoy la arrastra hacia una «dulce decadencia» que sólo podrá parar con la incorporación de las nuevas tecnologías en el sistema productivo, en: Cinco Días (18.6.2008).

28 GONZALEZ, F., Mi idea de Europa. RBA, Barcelona, 2010, p. 10.

29 GRAY, J., «Mucho más que una crisis financiera», El País (11.10.2008).

30 GNESOTTO, N., «L'Europe politique a-t-elle un avenir?», ROCARD, M. / GNESOTTO, N. (eds.), Notre Europe. Robert Laffont, París, 2008, p. 306; BATALLA, X., «2007: La globalización topa con la geopolítica», Anuario internacional CIDOB 2008. CIDOB, Barcelona, 2008, pp. 13-19; KAPLAN, R., «La venganza de la geografía», Foreign Policy en Español junio-julio 2009.

31 Éste es el diagnóstico que ofrece el economista jefe del HSBC (The Hongkong and Shanghai Banking Corporation) en su obra: KING, S. D., Losing Control. The Emerging Threats to Western Prosperity. Yale University Press, 2010.

32 MAHBUBANI, K., The New Asian Hemisphere: The Irresistible Shift of Global Power to the East. Public Affairs, Nueva York, 2008.

33 GRUPO DE REFLEXIÓN SOBRE EL FUTURO DE LA UE EN 2030, Proyecto Europa 2030. Retos y oportunidades. Consejo Europeo, mayo 2010, pp. 11 y 12. (www. hablamosdeeuropa.es/Documents/Informe_Grupo_Reflexión.pdf). 
Miedo a la globalización, miedo a la irrelevancia, miedo, en definitiva, al futuro. Así lo reconocía el Presidente del Consejo Van Rompuy en su discurso de noviembre de 2010 conmemorando la caída del muro de Berlín: «El mayor enemigo de Europa hoy en día es el miedo» ${ }^{34}$. Este miedo es reflejo de un sentimiento de inseguridad muy extendido que refleja una creciente incapacidad intelectual y política para hacer frente a los nuevos desafíos que plantea la sociedad internacional de la globalización ${ }^{35}$.

Indudablemente, Europa cuenta con sólidos argumentos para alimentar su pesimismo. Los problemas demográficos y económicos son desbordantes. Nos enfrentamos a una creciente pérdida de productividad en comparación con los Estados Unidos y el conjunto de economías de países emergentes. El envejecimiento demográfico plantea un dilema insoluble que nos obliga a optar entre la incorporación masiva de inmigrantes o la severa reforma (acaso desmantelamiento) del Estado del bienestar por no poder sostenerlo. Y a ello se le suma una dependencia energética crítica respecto de los combustibles fósiles. Pero como argumenta José Ignacio Torreblanca ${ }^{36}$, aunque estas tendencias sean claras, Europa no puede abandonarse a un determinismo fatalista. La Unión dispone de un cierto margen de tiempo y de maniobra para revisar su política y evitar que esta profecía se cumpla.

\section{Repensar la política europea}

La evolución registrada en los últimos años, los problemas acumulados y la emergencia de nuevos actores internacionales relevantes, obliga a Europa a replantearse los fundamentos sobre los que ha asentado su concep-

${ }^{34}$ Sus palabras literales fueron: «The biggest enemy of Europe today is fear. Fear leads to egoism, egoism leads to nationalism, and nationalism leads to war («le nationalisme,c'est la guerre» (F. Mitterrand)). Today's nationalism is often not a positive feeling of pride of one's own identity, but a negative feeling of apprehension of the others. Fear of 'enemies' within our borders and beyond our borders. It is a feeling all over Europe, not of a majority, but everywhere present.» VAN ROMPUY, H., «A Curtain went up» Berliner Europa-Rede, Pergamon Museum (Berlín, 9.11.2010) (PCE 256/10) (www.consilium.europa.eu/uedocs/cms_ data/docs/pressdata/en/ec/117623.pdf).

35 Javier Solana se ha lamentado de esta carencia política en sus propias filas: «la socialdemocracia, desgraciadamente, ha perdido terreno en Europa. No se dieron cuenta de lo que se avecinaba. Nadie lo hizo. Pero la socialdemocracia debió ser más consciente de los cambios que serían necesarios. La política en parte es saber "civilizar el futuro". La socialdemocracia no ha sabido hacerlo esta vez». SOLANA, J., Reivindicación de la política. Debate, Barcelona, 2010, p. 242.

36 TORREBLANCA, J. I., «La gobernabilidad del mundo y la fragmentación del poder europeo» en LAMO DE ESPINOSA, E. (coord.), Europa después de Europa, Academia Europea de Ciencias y Artes, Madrid, 2010, p. 369. 
ción del mundo y del papel que debía desempeñar en él. Como se afirmaba en el informe Proyecto Europa 2030: «Para que la Unión se asegure el futuro, tendrá que adaptar sus objetivos y políticas con objeto de hacer frente a este mundo en rápida transformación ${ }^{37}$. Esto implica que la UE debe replantearse tanto su interpretación de la globalización como el programa político que llevaba asociado, la gobernanza global y, desde luego, también el discurso con el que se proyecta en el mundo. No hacerlo puede acelerar el paso hacia la temida irrelevancia.

¿Las dos décadas transcurridas desde la desaparición de la URSS permiten confirmar la interpretación de que la globalización nos impulsa hacia el mundo post-moderno enunciado por Cooper? No lo parece. Asistimos, más bien, al auge de determinados Estados que han visto reforzados sus atributos de poder considerados en un sentido tradicional. La población, los recursos naturales, la economía productiva y el poder del gobierno vuelven a ser variables determinantes a la hora de configurar una nueva constelación de actores preeminentes: los BRICs en la actualidad y los N-11 en el futuro inmediato ${ }^{38}$.

En estas circunstancias de atribución divergente de los recursos de poder internacional resulta muy difícil que la UE pueda promocionar su propio modelo como pauta rectora del nuevo orden internacional. Jean Daniel, editorialista de Le Nouvel Observateur, ha proclamado el nacimiento de una «era posoccidental» ${ }^{39}$ en la cual, los países emergentes arrebatarían a Europa «la centralidad de una civilización que garantizaba su hegemonía intelectual», para concluir que «Occidente descubre que sin el poder ya no encarna el ideal».

La capacidad de atracción en que se ha apoyado el comportamiento internacional de la UE se está debilitando. La complaciente autopercepción europea de verse como una potencia benévola, «normativa» ${ }^{40}$, volcada en el ejercicio de su «poder transformador» ${ }^{41}$ capaz de atraer hacia su modelo político al resto de los actores internacionales debe ser también cuestionada.

37 Proyecto Europa 2030, p. 11.

${ }^{38}$ El término BRIC - acrónimo de Brasil, Rusia, India y China - se refiere al grupo de países emergentes que acabarían liderando el mapa económico mundial. El creador del término, Jim O'Neill, presidente de Goldman Sachs (gestión de activos), ha acuñando una nueva denominación: N-11, para referirse a los nuevos países emergentes (Bangladesh, Egipto, Indonesia, Irán, Corea, México, Nigeria, Pakistán, Filipinas, Turquía y Vietnam). A su juicio, son los países que cuentan con el mayor potencial para convertirse en los próximos protagonistas de la escena internacional. «Entrevista a Jim O’Neill», El País Negocios (13.3.2011).

39 DANIEL, J., «Nace la era posoccidental», El País (10.9.2010).

${ }^{40}$ MANNERS, I., «Normative Power Europe: A Contradiction in Terms?», Journal of Common Market Studies 2002 Vol. 40. n. ${ }^{\circ}$ 2, pp. 235-258.

${ }^{41}$ LEONARD, M., op. cit., nota 25, p. 17. 
A la Unión cada vez le resulta más difícil conservar esa fuente de poder blando, lo cual no quiere decir que haya desaparecido, aunque el retroceso sea manifiesto ${ }^{42}$. El caso más significativo tal vez sea la percepción que se tiene de la UE en Turquía. Cansada, posiblemente, del ambiguo trato recibido desde Bruselas y con un creciente optimismo alimentado por el auge de su economía, la opinión pública turca respecto a Europa no ha dejado de empeorar en los últimos años. En 2004, el $73 \%$ de los encuestados afirmaba que pertenecer a la UE sería positivo, pero el apoyo ha caído al 38\% en $2010^{43}$.

Esta pérdida de peso en la valoración de la opinión pública internacional no es sino reflejo de una creciente pérdida de relevancia internacional. Los ejemplos, desgraciadamente, han sido frecuentes en los últimos años. China se permitió cancelar unilateralmente la cumbre bilateral con la UE en noviembre de 2008 en respuesta a la entrevista entre Sarkozy y el Dalai Lama en Polonia y por el desaire cometido por los gobiernos de Alemania, Dinamarca, Francia y Holanda de no asistir a la inauguración de los Juegos Olímpicos de Pekín ${ }^{44}$. Por razones diferentes pero con idénticos resultados, también el presidente Obama suspendió la Cumbre UE-EE.UU. prevista para mayo de 2010 y que finalmente se retrasó para hacerla coincidir, en noviembre de ese mismo año, con la Cumbre de la OTAN en Lisboa. La triste comparecencia pública de Obama, Durão Barroso y Van Rompuy, apenas una hora después de haberse iniciado la reunión sin apenas conteni$\operatorname{dos}^{45}$, ilustra la relevancia que la actual presidencia estadounidense confiere a Europa en su acción diplomática. Y, desde luego, todas las alarmas euro-

${ }^{42}$ En la valoración sobre la influencia de distintos países que regularmente realiza la BBC, en su informe de 2010 se aprecia un salto atrás en las opiniones favorables respecto de la UE emitidas en países extra-europeos como Canadá y China (16 puntos de descenso en cada caso), India (13 puntos), Estados Unidos (12), Filipinas (11) o Australia (10), aunque siguen predominando las opiniones positivas, salvo en Turquía y Pakistán, donde las opiniones negativas respecto de Europa son predominantes (45\% y $30 \%$ de respuestas desfavorables, respectivamente). BBC World Survey 2010, p. 17 (www.worldpublicopinion.org/pipa/pipa/ pdf/apr10/BBCViews_Apr10_rpt.pdf).

43 Además, el porcentaje de turcos que afirman que Turquía debería cooperar con los países de la UE ha descendido nueve puntos, hasta representar tan sólo un $13 \%$. Por el contrario, quienes piensan que Turquía debería actuar en solitario en los asuntos internacionales representan un 34\%. GERMAN MARSHALL FUND, Transatlantic Trends 2010 (www. transatlantictrends.org).

44 FOX, J., GODEMENT, F., «A Power Audit of EU-China Relations», Policy Report - European Council on Foreign Relations. ECFR, Londres, 2009 (http://ecfr.eu/page/-/ documents/A_Power_Audit_of_EU_China_Relations.pdf).

${ }^{45}$ En palabras de Obama, la reunión «no es tan excitante como otras, porque básicamente estamos de acuerdo en todo». El encuentro se celebró al término de la cumbre de la OTAN, el Consejo OTAN-Rusia y la cumbre de la ISAF (Afganistán). Vid. «Washington da la espalda a la UE», en: El País (21.11.2010). 
peas se dispararon ante el «desastre increíble» que supuso la Cumbre sobre el Clima celebrada en Copenhague en diciembre de $2009^{46}$. Pese a que la cita reunió a más de 150 jefes de Estado y de gobierno, solo se alcanzó un pacto de mínimos cuyo texto fue concluido en una reunión celebrada a puerta cerrada entre los líderes de EE.UU., China, India, Brasil y Sudáfrica, sin que participara un solo representante europeo.

Desde el propio Washington se ha extendido el convencimiento de que la integración europea alcanzó en la pasada década su «máximo nivel» ${ }^{47}$ y ha dejado de ser «un actor de primer nivel» ${ }^{48}$ que se encuentra irremisiblemente condenado a la «marginación geopolítica» ${ }^{49} \mathrm{Si}$ esta es la opinión dominante que tienen de nosotros nuestro principal socio y aliado ¿qué impresión no se tendrá desde el resto del mundo? Es posible, como afirma Mahbubani, que Europa no se haya dado cuenta de hasta qué punto se está volviendo «irrelevante $»^{50}$.

Debemos reconocer que el proyecto europeo de gobernanza global representa un desafío extraordinario para la política exterior de la UE en una dimensión múltiple. En primer lugar debe impulsar la reforma de las organizaciones internacionales para que puedan asumir la gestión de los asuntos mundiales de manera eficaz. Para logarlo debe desarrollar una fuerte capacidad de liderazgo que le permita atraer hacia sus puntos de vista las posiciones defendidas por el resto de los actores. Pero además, debe profundizar su integración política, atribuyendo a la Unión la influencia y visibilidad que hasta ahora radica en los Estados miembros. Y todo ello tratando de ganar influencia en un entorno de pérdida relativa de poder internacional. La tarea es titánica, se mire por donde se mire. Si analizamos la actuación europea realizada en los últimos años en las instituciones centrales del sistema internacional (NN.UU. y las organizaciones de Bretton Woods) los resultados obtenidos nos deben obligar a reflexionar si la estrategia diseñada se

46 Según el informe del embajador estadounidense enviado al Departamento de Estado desvelado por Wikileaks, el Presidente del Consejo Van Rompuy calificó la cita como «un desastre increíble» en el que Europa fue «totalmente excluida» y «maltratada». El País (4.12.2010) (http://www.elpais.com/articulo/internacional/Van/Rompuy/Copenhague/fue/ desastre/cumbres/funcionan/elpepiint/20101204elpepiint_3/Tes).

${ }^{47}$ FRIEDMAN, G., La próxima década. Los líderes y las potencias que determinarán el mundo que viene. Destino, Barcelona, 2011, p. 200 (el autor es el actual presidente de Stratfor, la principal compañía privada de predicción geoestratégica de los Estados Unidos).

48 HAAS, R., «A waning Europe means less to America», Financial Times (13.5.2010) (el autor es el actual presidente del Council on Foreign Relations de los Estados Unidos).

49 SHAPIRO, R. J., 2020. Un nuevo paradigma. Tendencias, Barcelona, 2009, p. 46 (el autor fue Subsecretario de Comercio durante la presidencia de B. Clinton).

${ }^{50}$ MAHBUBANI, K., «The Case Against the West», Foreign Affairs 87 n. ${ }^{\circ}$ 3, 2008, pp. 111-124 (www.foreignaffairs.com/articles/63402/kishore-mahbubani/the-case-againstthe-west). 
ajusta a los medios de que la Unión dispone, si las formas de actuación de la UE se corresponden efectivamente con los objetivos señalados y, por último, si estos objetivos colectivos son asumidos, con todas las consecuencias, por parte de los Estados miembros.

\section{La pérdida de capacidad de atracción europea en Naciones Unidas}

En los últimos años se ha manifestado una corriente de voto en el seno de la Asamblea General de Naciones Unidas (AG) que tiende a rechazar las propuestas relativas a los Derechos Humanos planteadas por los Estados europeos. Según un estudio realizado por el European Council on Foreign Relations $(\mathrm{ECFR})^{51}$ sobre esta cuestión, haciendo un seguimiento exhaustivo de todas las votaciones realizadas en la AG sobre materias que afectan a la defensa de los Derechos Humanos efectuadas desde 2008, la pérdida de influencia europea es incontestable. El estudio identifica cuatro categorías de países en función del sentido de su voto:

- Países europeos vecinos de la UE: se trata de 16 Estados que desde el fin de la guerra fría han votado en el sentido de la Unión y que, a partir de 2008, han mantenido posiciones más autónomas, cuando no directamente contrarías a las defendidas por la Unión. El caso de Kosovo y la actitud de Serbia han sido decisivos en ese cambio.

- Países no europeos normalmente alineados con la UE (entre los que se incluye a EE.UU.). Este grupo presenta una coincidencia en el sentido del voto entre el 75 y el $51 \%$ de las ocasiones. El número de sus integrantes tiende a reducirse gradualmente. De 44 países en 2008 pasó a 32 en 2009 y se redujo a 22 en 2010. El mayor número de deserciones se ha localizado en África y Asia, quedando reducidos los apoyos europeos prácticamente a América Latina o Israel.

- Países cuyo voto fluctúa, aunque suelen votar en el sentido de la UE entre un 26 y un 50\% de las ocasiones. Al igual que en el grupo anterior, la tendencia es a disminuir (de 86 pasaron a 77 en 2009), en particular por el comportamiento de los países islámicos.

- Por último se encontraría el grupo de países que casi nunca votan con la UE (menos del 35\% de las votaciones sobre Derechos Humanos).

51 Se trata de una serie de estudios sucesivos sobre el mismo tema: GOWAN, R., BRANTNER, F., A Global Force for Human Rights? An Audit of European Power at the UN; The EU and human rights at the UN -2009 review; y The EU and human rights at the UN: 2010 review. ECFR, 2008, 2009 y 2010, respectivamente (ecfr.eu). Una versión reducida del primer informe puede consultarse en español en: GOWAN, R., BRANTNER, F., «UE, derechos humanos y Naciones Unidas», Política Exterior n. ${ }^{\circ} 126 / 2008$, pp. 65-80. 
Este apartado ha observado un crecimiento espectacular, de 19 Estados pasaron a 40 en 2009 y 61 en 2010. En el seno de este grupo pueden distinguirse dos colectivos cuyo voto tiende a converger. Por un lado aquellos países que por razones de fe dan prioridad a los principios religiosos colectivos frente a los derechos individuales, como por ejemplo los países musulmanes, aunque no sólo ellos. Por otra parte se encontrarían aquellos países que defienden el soberanismo frente a las reinterpretaciones «post-nacionales» de la soberanía, entre los que se encuentran China, Rusia, así como un grupo nada despreciable de gobiernos con historial contrastado en violaciones de Derechos Humanos. En buena medida, ambos grupos tienden a superponerse.

Los resultados de estos informes resultan reveladores en muchos aspectos. En primer lugar, por el foro en el que se producen, Naciones Unidas, y en segundo lugar, por el tema que es objeto del creciente rechazo, los Derechos Humanos. La centralidad absoluta de ambas cuestiones en los objetivos y en la estrategia de la UE están fuera de toda discusión. Por esta razón bien puede tomarse el sentido de las votaciones en el seno de la AG como una desautorización hacia la UE que pone en entredicho su capacidad de liderazgo internacional para impulsar el orden internacional que propugna en la dirección de la gobernanza global $^{52}$.

Hay más ejemplos que permiten ilustrar esta corriente de voto en la Asamblea General contrario a la Unión, por lo que no puede ser considerado como un mero episodio. Señalemos tan sólo dos casos: la Responsabilidad de Proteger (RdP) y el cambio de estatuto de la UE ante la Asamblea.

Sabida es la resistencia que ha encontrado la RdP para ser aceptada como una nueva norma internacional. Desde el momento en que fue sometida a debate, al inicio del siglo, un número significativo de actores la han rechazado por considerarla un instrumento al servicio de los Estados más poderosos para legitimar su capacidad de ingerencia sobre el resto del mundo. El principal foco de oposición ha partido del grupo de Estados que integran el Movimiento de Países No Alineados, organizado en la ONU bajo título de G-77.

En la última ocasión en que fue debatida la RdP en NN.UU., en julio de 2009 , el debate plenario en la $\mathrm{AG}^{53}$ se resolvió con una muy escueta resolución que reflejaba las enormes diferencias que siguen enfrentando a de-

52 Aunque los autores de estos informes señalan como principal causa la introspección de la diplomacia europea, volcada en la coordinación entre los Estados miembros, que no facilita desarrollar estrategias que permitan incorporar a otros Estados. Ibid., p. 76.

53 More than 40 Delegates Express Strong Scepticism, Full Support as General Assembly. Nueva York, 24 de julio de 2009 (GA/10849) (www.un.org/News/Press/docs/2009/ ga10849.doc.htm). 
fensores y detractores ${ }^{54}$. Entre los que integran este último grupo han sido identificados colectivos que atienden a razones diferentes ${ }^{55}$ pero que encuentran un punto de encuentro, con su voto negativo, en su oposición y resistencia ante las propuestas occidentales, un sentido de voto opositor que tiende a ser capitalizado por los países emergentes.

Algo parecido ocurrió cuando la Asamblea General rechazó, en septiembre de 2010, la propuesta europea de modificar las condiciones de representación de la UE ante Naciones Unidas para adaptarla a la nueva estructura institucional de la acción exterior europea establecida por el Tratado de Lisboa $^{56}$. Desde su entrada en vigor, en diciembre de 2009, la delegación de la Comisión Europea ante Naciones Unidas se transformó en delegación de la UE, compartiendo la función de representante de la Unión ante NN.UU. con la Misión Permanente del país que ocupa la presidencia rotatoria del Consejo. En septiembre de 2010 la UE solicitó modificar su estatuto de observador (que no le daba derecho a tomar la palabra) para permitir a la Alta Representante hablar en nombre de los Estados miembros ante la $\mathrm{AG}$, a nivel interministerial. Como es conocido, la propuesta fue rechazada. La lista de países que votaron en contra de la propuesta europea no sólo estaba integrada por los miembros de organizaciones regionales que como la Unión Africana o la ASEAN aspiraban a obtener un tratamiento semejante. También incluía a aliados tradicionales e interlocutores internacionales claves, como Australia, Brasil, Canadá, China, Federación Rusa, India o Nueva Zelanda ${ }^{57}$.

54 «La Asamblea General (...) toma nota del informe del Secretario General y del oportuno y productivo debate» $\mathrm{y}$ «decide seguir examinando la responsabilidad de proteger». NN.UU. - ASAMBLEA GENERAL: Resolución 63/308 - Responsabilidad de Proteger, Nueva York, 14 de septiembre de 2009 (A/RES/63/308) (http://daccess-dds-ny.un.org/doc/ UNDOC/GEN/N09/513/41/PDF/N0951341.pdf?OpenElement).

${ }^{55}$ Entre los críticos puede distinguirse a aquellos gobiernos que se sienten «amenazados» por la aplicación del nuevo principio. En segundo lugar se situaría el grupo más numeroso, denominado «anti-imperialista» cuyo argumento principal es destacar el valor instrumental que la RdP tiene para las grandes potencias occidentales que tratan de mantener su tradicional capacidad de influencia amparándola ahora en una interesada y selectiva defensa de los Derechos Humanos. Un tercer grupo estaría formado por los «legalistas» que se oponen a cualquier acto de injerencia externa apelando al principio de soberanía. Y por último se encontrarían los «escépticos» y los «dubitativos» que consideran al principio imposible de aplicar de una manera imparcial, justa y equitativa. FRIDE, INTERMÓN-OXFAM, Responsabilidad de proteger: De las ideas a la capacidad (marzo de 2009). pp. 9-10 (www.intermonoxfam.org/ cms/HTML/espanol/3265/090316_R2P_report_SP.pdf).

56 Participation of the European Union in the work of the United Nations, 31 de agosto de 2010 (A/64/L.67).

57 Un análisis detallado sobre la votación en: EMERSON, M., WOUTERS, J., «The EU's Diplomatic Debacle at the UN. What else and what next?», CEPS Commentary (octubre 2010), (www.ceps.eu/book/eu\%E2\%80\%99s-diplomatic-debacle-un-what-else-and-whatnext). 
Aunque la propuesta de la UE fue rechazada, se logró el compromiso de seguir discutiéndola, lo que no evitó que numerosos observadores lo consideraran un fracaso diplomático para la Unión ${ }^{58}$. Por fortuna, y después de un esfuerzo diplomático considerable, la Unión consiguió un gran éxito al lograr modificar su estatuto de observador ante la Asamblea de NN.UU. en una nueva votación celebrada el 3 de mayo de $2011^{59}$. Con 180 votos a favor, ninguno en contra (diez países no votaron, entre ellos Libia o Venezuela) y dos abstenciones (Siria y Zimbabwe), el acuerdo abre la puerta a que otras organizaciones regionales logren también ese mismo estatuto, lo cual ha sido clave para desbloquear la votación.

Con el nuevo estatuto de observador ${ }^{60}$ los representantes de la UE adquieren el derecho a intervenir en la Asamblea General, pudiendo presentar propuestas y enmiendas aprobadas por los Estados miembros de la UE y ejercer el derecho de réplica, aunque no podrán votar ni presentar candidatos ni recurrir las decisiones del presidente de la Asamblea. Constituye, sin duda, un gran éxito para el desarrollo de la política exterior de la Unión tras la entrada en vigor del Tratado de Lisboa, que permite aumentar la coherencia interna y ganar mayor visibilidad en la escena mundial, aunque no se vea afectada la representación en el Consejo de Seguridad, lo cual constituye una excepción verdaderamente significativa.

Siendo indudablemente positivo el resultado de esta votación, y las oportunidades políticas que se abren a partir de ahora para la Unión, está por ver el desarrollo futuro que pueda tener en el papel desempeñado por la UE ante la ONU. Ojalá represente un hito que permita invertir la negativa tendencia de rechazo registrada en los últimos años, pero para logarlo Europa tendrá que desplegar una actividad diplomática firme y constante. Y, desde luego, tampoco queda cerrada la posibilidad de que los Estados miembros mantengan posturas divergentes en este foro, especialmente ante el Consejo de Seguridad. Como se puso de manifiesto en la votación en la que se decidió autorizar el uso de la fuerza contra Libia ${ }^{61}$, el Tratado de Lisboa no es instrumento suficiente para evitar las divergencias entre los socios

${ }^{58}$ EMERSON, M., WOUTERS, J., op. cit.; y DRIESKENS, E., VAN SCHAIK, L. (eds.), The European External Action Service: Preparing for Success. Netherlands Institute of International Relations, 2010, p. 8 (www.clingendael.nl/publications/2011/20110200_clingendael_ paper_1.pdf).

59 General Assembly, in Recorded Vote, Adopts Resolution Granting European Union. Right of Reply, Ability to Present Oral Amendments, 3 de mayo de 2011 (GA/11079/Rev. 1*).

60 Participación de la Unión Europea en la labor de las Naciones Unidas, 10 de mayo de 2011 (A/RES/65/276).

${ }^{61}$ Resolución 1973. El Consejo de Seguridad aprueba "zona de exclusión aérea" en Libia, Nueva York, 17 de marzo de 2011 (SC/10200) (www.un.org/News/Press/docs/2011/ sc10200.doc.htm). 
(divergencias no anecdóticas, precisamente): Alemania se abstuvo, junto a Rusia, en la Resolución propuesta por Francia y Reino Unido.

\section{La difícil reforma de las organizaciones económicas internacionales}

Antes de que estallara la crisis en 2008 ya era evidente la necesidad de un gobierno económico a nivel mundial, pero también en el seno de la propia Europa para asegurar el buen gobierno del euro. La crisis convirtió esa necesidad en urgencia haciendo de la economía un elemento central de la agenda mundial desde entonces. Entre las iniciativas que se han impulsado para lograr ese fin destaca, por encima de todas, el denominado G-20 ampliado: un instrumento multilateral que, al menos en sus inicios, daba la impresión de poder satisfacer todas las necesidades de gobierno económico planteadas. Sin embargo, los resultados logrados en las cinco ocasiones en que se ha reunido hasta ahora este foro informal no han satisfecho las expectativas despertadas en sus inicios cuando se habló, nada menos, de refundar el orden económico internacional ${ }^{62}$.

La gestión política de la crisis ha supuesto para los países europeos una durísima prueba de la que no están logrando salir airosos, al menos de momento. Este enorme desafío se manifiesta en dos planos simultáneos e interrelacionados: el papel desempeñado por la UE en el G-20 y la reforma de las instituciones económicas internacionales. Vayamos por partes.

Con respecto al G-20 no quiero incidir sobre los magros resultados obtenidos, aunque algunos de ellos hayan sido decisivos como poner freno al proteccionismo y controlar la «guerra de divisas». Con toda seguridad, las expectativas depositadas en este foro superaban a sus capacidades, teniendo en cuenta el entorno particularmente difícil en que se han desarrollado sus trabajos. Por el contrario, lo que quiero destacar son las dificultades objetivas a las que se enfrenta la materialización práctica de la gobernanza económica mundial. Una de las ventajas del G-20 era su carácter informal. En principio se pensaba que esa característica lo ponía a salvo de los constreñimientos procedimentales, ganando en libertad de acción. Una consecuencia derivada de lo anterior era su falta de legitimidad para adoptar decisiones, por muy representativa que fuera su composición en términos demográficos y de PIB. En todo caso, se pensaba que la falta de legitimidad sería compensada con los resultados: si su gestión se revelaba eficaz, el G-20 se consolidaría. La esperanza consistía, en definitiva, en logar transformar un

62 MORENO GARCÍA, P. , Dos años de Cumbres del G-20: adagio spiccato. Real Instituto Elcano (Análisis n. ${ }^{\circ}$ 162/2005 de 15.11.2010). 
multilateralismo eficaz de legitimidad dudosa en otro institucionalizado y legitimado por su buena gestión. Pero ese tránsito no se ha consumado. Antes al contrario, la reunión de Toronto (junio 2010) demostró los límites de este foro para resolver los problemas económicos mundiales ${ }^{63}$, aunque en Seul (noviembre 2010) se hayan mejorado las perspectivas.

La UE ha desempeñado en este proceso un papel prácticamente irrelevante. La presencia en el G-20 de los principales países europeos, que no todos pertenecen al euro, reduce a la Unión a la función de mero observador, aunque cuente con capacidad de voto. De forma habitual las negociaciones son mantenidas por los gobiernos nacionales, que tienden a defender sus propios intereses, no siempre coincidentes. Como consecuencia, la cohesión y coherencia europeas quedan relegadas. En palabras de Pedro Solbes:

«Los gobiernos europeos han usado el G-20 para atender sus propios intereses en vez de fomentar una cooperación multilateral más extendida y equilibrada. Europa no sólo está sobrerrepresentada en el Grupo, sino que no ha habido una coordinación sistemática entre los Estados miembros. Pero, ¿cómo pretende la Unión que otras potencias apliquen los principios multilaterales que ella misma ignora? ${ }^{64}$

La falta de coordinación entre los Estados europeos y la sobrerrepresentación son también los principales problemas a los que se enfrenta la Unión en la reforma de las organizaciones económicas internacionales. Sobre esas bases resulta ilusiono pretender ejercer un liderazgo europeo con capacidad para atraer a sus posiciones a los demás actores.

En las instituciones de Bretton Woods (FMI y Banco Mundial), resulta manifiesta la ausencia de una posición común europea, la sobrerrepresentación de los Estados miembros y sus resistencias a ceder «sillas» y porcentajes de voto a otras partes del mundo, como si su obstinación les sirviera para prolongar su influencia internacional. El problema que se plantea es, por tanto, doble. Por un lado, es necesario superar las resistencias nacionales a consumar una integración efectiva de la Unión en su proyección internacional (consecuencia derivada del Tratado de Lisboa) lo cual lleva implícito una dilución de la visibilidad e influencia de los Estados nacionales. Por otro, los Estados europeos deben impulsar unas reformas cuyo resultado, a la postre, se traduce en una pérdida de su poder internacional consi-

63 TUGORES QUEL, J., Cumbre del G-20: ¿y después de Toronto? Real Instituto Elcano (Análisis n. ${ }^{\circ}$ 112/2010 de 30.6.2010).

${ }^{64}$ SOLBES, P., «La reforma de la gobernanza económica mundial», MARTININGUI, A., YOUNGS, R. (eds.), Desafios para la política exterior europea en 2011. FRIDE, Madrid, 2010, p. 21. 
derado tanto en términos individuales como colectivos. La esperanza radica en que ese poder, aunque menor, pueda ser más eficaz en la defensa de los intereses comunes.

La sobrerrepresentación europea es manifiesta en todos los ámbitos: en el G-7, donde cuatro de sus miembros son europeos (Alemania, Francia, Italia y R. Unido ${ }^{65}$; en el G-20 donde previsiblemente los europeos acabarán ocupando seis plazas (las cuatro anteriores, más la Presidencia del Consejo de la UE y el puesto ocupado por España, si finalmente logra consolidarse); así como en las instituciones de Bretón Woods. La tabla 2 refleja las modificaciones en la asignación de voto aprobadas en las reformas sucesivas del FMI (2006, 2008 y 2010) y del Banco Mundial (2010), relacionándolas con la participación de los distintos actores en el PIB mundial actual, y en su proyección dentro de una década.

\section{Tabla 2}

Asignación de votos en el FMI y el BM (en relación con la participación en el PIB mundial)

\begin{tabular}{|c|c|c|c|c|c|c|c|c|}
\hline & \multicolumn{3}{|c|}{$\begin{array}{l}\text { FMI } \\
\% \text { voto }\end{array}$} & \multicolumn{2}{|c|}{$\begin{array}{c}\text { BM } \\
\% \text { voto }\end{array}$} & \multicolumn{3}{|c|}{$\begin{array}{c}\text { Participación } \\
\text { en el PIB mundial } * \%\end{array}$} \\
\hline & $\begin{array}{l}\text { Pre-Singapur } \\
\text { sept } 2006\end{array}$ & $\begin{array}{l}\text { Post- } \\
2008\end{array}$ & $\begin{array}{l}\text { Post- } \\
2010\end{array}$ & $\begin{array}{l}\text { Hasta } \\
2010\end{array}$ & $\begin{array}{l}\text { Post- } \\
2010\end{array}$ & 2010 & 2015 & 2020 \\
\hline UE-27 & 32.5 & 30.9 & 29.4 & 28.5 & 26.3 & 20.8 & 18.7 & 16.6 \\
\hline EE.UU. & 17 & 16.7 & 16.5 & 16.4 & 15.8 & 20.2 & 18.3 & 16.4 \\
\hline Brasil & 1.4 & 1.7 & 2.2 & 2.1 & 2.2 & 2.9 & 2.8 & 2.7 \\
\hline Rusia & 2.7 & 2.3 & 2.5 & 2.8 & 2.8 & 3.0 & 3.0 & 2.9 \\
\hline India & 1.9 & 2.3 & 2.6 & 2.8 & 2.9 & 5.2 & 6.1 & 7.0 \\
\hline China & 2.9 & 3.8 & 6.07 & 2.8 & 4.4 & 13.3 & 16.9 & 20.6 \\
\hline $\begin{array}{l}\text { Total } \\
\text { BRICs }\end{array}$ & 8.9 & 11.1 & 14.07 & 10.5 & 12.3 & 24.4 & 28.8 & 33.2 \\
\hline
\end{tabular}

* Estimado sobre la paridad de poder adquisitivo en 2010.

Fuente: EMERSON, M., Upgrading the EU's role as global actor. ECFR, 2011, pp. 71-74. IMF, «Quota and Voting Shares Before and After Implementation of Reforms Agreed in 2008 and 2010» (www.imf.org/external/np/sec/pr/2011/pdfs/quota_tbl.pdf)

65 En abril de 2011, el FMI hizo público su informe sobre las previsiones económicas para 2011. En el nuevo ranking entre las siete primeas economías del planeta ya no figuran Canadá e Italia que han sido sustituidas por China y Brasil. «España cae a la $12^{\mathrm{a}}$ economía mundial y no volverá a estar entre las 10 más grandes en años», El País (11.4.2011). 
El resultado es muy ilustrativo. Los países europeos han cedido dos de las nueve «sillas» de directores ejecutivos que hasta ahora ocupaban (de un total de 24) y han transferido parte de sus derechos de voto (un 3,1\% en el FMI y un 2,2\% en el BM) que han beneficiado principalmente a los BRICs, sin que la participación estadounidense apenas haya variado. Pese a todo, el peso de los países europeos sigue siendo superior al doble del conjunto de los BRICs, cuando su aportación al PIB mundial ya es casi cuatro puntos inferior. Los datos ponen de relieve que estas reformas difícilmente pueden considerarse como definitivas. Si se confirman las previsiones sobre la evolución de la economía mundial los países europeos deberán efectuar nuevas cesiones hasta ajustar su representación a su peso económico real, si en verdad se quiere institucionalizar una gobernanza económica mundial.

¿De verdad que estos cambios permiten reclamar a la UE el liderazgo en la gobernanza mundial? Por mucho que logremos maquillar las maniobras llevadas a cabo por los gobiernos europeos para minimizar sus pérdidas, difícilmente puede hablarse de mayor integración entre ellos ni de aumento de su prestigio exterior como consecuencia de sus acciones. Con respecto a esta cuestión del liderazgo, las circunstancias han querido que la diplomacia europea se enfrente a un imprevisto tour de force si quiere conservar la presidencia del FMI. Por primera vez desde su creación un candidato no europeo (el gobernador del Banco Central de México, Agustín Carstens) disputa el cargo a la candidata europea (la ministra francesa de Finanzas, Christine Lagarde). Aunque la privilegiada posición europea seguramente no se verá amenazada en esta ocasión, gracias sin duda al apoyo estadounidense, el hecho nos sitúa ante un escenario de pérdida de influencia internacional que aunque previsto, ahora se manifiesta inminente.

\section{Reflexiones finales}

«Mais il y avait aussi la prise de conscience que la mondialisation change de visage. (...) les nouveaux acteurs mondiaux ne partagent pas toujours nos intérêts, ni notre vision du monde. Cela nous affecte. Si nous voulons, en tant qu'Europe, défendre nos intérêts et nos valeurs, il faut prendre conscience de cette réalité» ${ }^{66}$.

66 VAN ROMPUY, H., «Non pas renationalisation de la politique europeenne, mais europeisation de la politique nationale» Discours à l'invitation de «Notre Europe» Paris, Grand amphi de Sciences-Po (París, 20.9.2010) (www.consilium.europa.eu/uedocs/cms_data/docs/ pressdata/fr/ec/116622.pdf). 
El Presidente del Consejo, Van Rompuy, pronunciaba estas palabras en septiembre de 2010 ante un foro europeísta por antonomasia como es la Fondation Notre Europe, presidida por Jacques Delors. En ellas se encuentra el eco de los argumentos que he tratado de exponer en las páginas precedentes.

1. No hemos acabado de comprender la dinámica internacional desatada por ese proceso al que denominamos globalización. Las interpretaciones sucesivas que se han ido dando de este fenómeno son superadas por una realidad cuyos fundamentos aparecen transformados cada poco tiempo, imponiendo una velocidad a los cambios que acaba desbordando nuestra capacidad para interpretarlos. En todo caso, debemos ser conscientes de estas debilidades intelectuales para aprehender una globalización que «cambia de cara» y seguir analizando un fenómeno cuya existencia es tan irrebatible, como su funcionamiento nos resulta indescifrable. Por eso no debemos abandonarnos al pesimismo colectivo. La globalización de los noventa parecía consagrar la supremacía de Occidente, al tiempo que la crisis de 1997 condenaba a los países asiáticos a los márgenes del sistema. Una década más tarde los términos aparecen invertidos y aquello que entonces se percibía como un instrumento de dominación del Norte sobre el Sur, es contemplado ahora como una amenaza a la prosperidad europea. Ante estos cambios Europa se siente atenazada por un temor que condiciona su respuesta: que su debilidad económica, en términos comparativos, la conduzca a la marginalidad política. Pero el futuro no está escrito, aunque las tendencias de fondo nos indiquen un horizonte de dificultades, nuestro destino no está determinado. El papel internacional que la UE pueda llegar a desempeñar dependerá de lo que los europeos seamos capaces de hacer.

2. Cada vez hay más actores relevantes cuya visión del mundo y sus propuestas para organizar la convivencia internacional divergen de la concepción europea. Casi con total seguridad, éste será un rasgo permanente del sistema internacional futuro. Si Europa reconoce que ha perdido la hegemonía intelectual que ha detentado durante siglos. Si asume que «sin el poder ya no encarna el ideal», necesariamente deberá sacar las consecuencias que se derivan de esta nueva realidad y adaptar su acción política a las nuevas circunstancias. Porque una cuestión es que el nuevo mundo de la globalización vaya a ser «postoccidental» y otra bien distinta es que acabe siendo «anti-occidental». Europa puede ver cómo los valores que encarna y que trata de proyectar como ejes de su acción exterior no encuentran la admiración y emulación que busca. Pero muy diferente sería si la indiferen- 
cia diera paso al rechazo. ¿Existe el riesgo de que nos enfrentemos a una corriente de opinión antieuropea? Claro que existe, como es muy posible que pueda convivir con una creciente opinión antieuropeísta dentro de nuestras fronteras. El anti-occidentalismo tiene unas sólidas raíces políticas e intelectuales asentadas durante la época de la lucha por la independencia entre los pueblos víctimas de la dominación colonial. Y ese rechazo se puede reavivar.

Europa tiene una percepción de sí misma absolutamente narcisista y complaciente que no comparte, necesariamente, el resto de la humanidad. Vista desde fuera, en muchas ocasiones irrita la actitud europea, por moralizante y entrometida. Por nuestro persistente sentimiento de superioridad y autosatisfacción ${ }^{67}$. Y, desde luego, no se nos asocia exclusivamente con el Estado del bienestar y sus virtudes democráticas, sino con el haber sido las antiguas metrópolis. Europa es vista desde su periferia como una fortaleza inexpugnable: proteccionista en el comercio, cada vez más inaccesible para el emigrante, y más desconfiada con el extranjero. Nuestra latente y creciente xenofobia se comparece mal con nuestro discurso humanista de solidaridad y cooperación. Y todavía nos asombra el éxito logrado por otros actores, como China, en su proyección sobre el continente africano aplicando unas prácticas pragmáticas, sin querer dar lecciones morales y sin entrometerse en los asuntos internos de los países receptores ¿Nos puede sorprender acaso que China, un país sin pasado como potencia colonial en África, acabe desplazando a las antiguas potencias europeas en su influencia sobre ese continente? ${ }^{68}$.

3. Como decía Van Rompuy «es necesario tomar conciencia de esta realidad» y repensar nuestra acción política. Pero el éxito de países como China no debe llevarnos a la conclusión de que tenemos que imitarla. Europa no puede renunciar a ser ella misma, pero debería ser más modesta en sus aspiraciones exteriores (entre influir y liderar media una gran distancia) y reconsiderar las políticas que desarrolla para no incurrir en una suerte de excepcionalismo a la euro$p e a^{69}$ según el cual todas nuestras acciones atienden exclusivamente a nuestros elevados principios.

${ }^{67}$ CORM, G., Europa y el mito de Occidente. Península, Barcelona, 2010.

${ }^{68}$ LAFARGUE, F., «La Chine en Afrique : une réalité à nuancer», Diploweb.com La Revue Géopolitique (10.8.2009) (www.diploweb.com/La-Chine-en-Afrique-une-realite-a.html).

${ }^{69}$ Equiparable al desarrollado por los Estados Unidos como rasgo distintivo de su comportamiento internacional. Vid. LIPSET, S. M., El excepcionalismo norteamericano, Fondo de Cultura Económica, México, 2000. 
«Este discurso de que nosotros defendemos valores es una simpleza; defendemos intereses, que son los europeos, en un marco de valores que son los nuestros» ${ }^{70}$.

Así se expresaba Felipe González señalando un camino que conduce a Europa por la senda de la normalización en tanto que actor internacional: adoptar un comportamiento como el de cualquier otro actor, en defensa de sus intereses y atendiendo a sus propios valores.

Posiblemente, el mejor medio para iniciar esa senda de normalización fuera empezar por aplicarnos a nosotros mismos los principios proclamados de la gobernanza global y que tan difíciles resultan de emplear en la actual crisis del euro: la solidaridad colectiva, la construcción de soberanías compartidas sobre un número creciente de políticas, la búsqueda de un interés nacional europeo que implique someter los intereses particulares a un bien común compartido ${ }^{71}$. En suma, la re-europeización de las políticas nacionales y el abandono de la deriva nacionalista que parece arrastrarnos desde el inicio de la crisis. Mientras Europa no acabe de consumar su integración efectiva y desarrolle dentro de sus fronteras y en su comportamiento internacional los principios que proclama, difícilmente podrá proyectarse hacia el exterior de una forma eficaz reclamando el liderazgo mundial al que aspira.

70 Entrevista a Felipe González, El País (22.11.2009).

${ }^{71}$ GNESOTTO, N., L'Europe a-t-elle un avenir stratégique? Armand Colin, Paris, 2011, p. 203. 